\title{
TIME OF APPEARANCE OF GOBLET CELLS IN HUMAN SMALL INTESTINE
}

\author{
Kaini Pfoze ${ }^{1}$, Huidrom Rajshree ${ }^{2}$
}

${ }_{1}^{1}$ Associate Professor, Department of Anatomy, Jawaharlal Nehru Institute of Medical Sciences, Porompat, Imphal, Manipur. ${ }^{2}$ Assistant Professor, Department of Anatomy, Jawaharlal Nehru Institute of Medical Sciences, Porompat, Imphal, Manipur.

\section{BACKGROUND}

\section{ABSTRACT}

Goblet cells form an important component of the lining epithelium of the small intestine. The time of appearance of goblet cells in the human foetus, however, is not widely reported. Few authors have reported the appearance of these cells at 9 - 10 weeks of gestational age. This study is an attempt to find out the exact time of appearance of goblet cells in the human small intestine.

\section{MATERIALS AND METHODS}

After obtaining clearance from the Ethics Committee, specimens of small intestine were procured from 50 aborted foetuses and processed for histological observations. Haematoxylin and Eosin stain was used for staining the prepared slides.

\section{RESULTS}

Goblet cells were observed at 9 weeks of gestational age in the small intestine of a few foetuses. At 12 weeks of development, goblet cells were seen in all the foetal specimens studied.

\section{CONCLUSION}

The present study found that goblet cells in the human small intestine started appearing before 9 weeks of gestational age in some foetuses. Goblet cells start to appear before 9 weeks in few foetuses and in most of the foetuses it will appear by 12 weeks.

\section{KEYWORDS}

Small Intestine, Foetus, Epithelial Cells, Goblet Cells, Time of Appearance.

HOW TO CITE THIS ARTICLE: Pfoze K, Rajshree H. Time of appearance of goblet cells in human small intestine. J. Evolution Med. Dent. Sci. 2018;7(17):2099-2103, DOI: 10.14260/jemds/2018/470

\section{BACKGROUND}

Goblet cells are mucus secreting unicellular glands scattered among the absorptive cells of the intestinal epithelium. Their name is suggestive of the shape of the cell in routine histological preparation. The apex has an expanded C-shaped rim of cytoplasm called the theca, filled with secretion and a narrow base extending downwards to the basal lamina. They produce mucin for the lubrication of the intestinal contents and protection of the epithelium. Stem cells occur in a zone occupying the middle region of the crypts and provide the source of most of the cell types of the intestinal epithelium. They have fewer and more irregular microvilli than do the columnar cells. These cells multiply at the rate of 1 cell per 100 hours, one of the most rapid proliferation rates in the body.[1,2]

Goblet cells have elongated, basal nuclei and an apical region containing many membrane-bound mucin granules. When tissues are fixed in Formalin and also many other fixatives, these granules swell rapidly to produce the characteristic but artefactual goblet like shape. When fixed more rapidly, e.g. by quick freezing, they are more columnar or conical in form. Their apical surface bears a few short microvilli and in the supranuclear region there is a prominent Golgi apparatus with granular endoplasmic

'Financial or Other Competing Interest': None.

Submission 20-01-2018, Peer Review 06-04-2018,

Acceptance 12-04-2018, Published 23-04-2018.

Corresponding Author:

Dr. Kaini Pfoze,

Department of Anatomy,

Jawaharlal Nehru Institute of Medical Sciences,

Porompat, Imphal East-795005, Manipur.

E-mail: kainipfoze@yahoo.com

DOI: $10.14260 /$ jemds $/ 2018 / 470$ reticulum more basally situated. Their secretions are important in the chemical and mechanical protection and lubrication of the intestinal wall, and also in its immune defense, since class IgA antibodies are also secreted. At their bases and sides, the goblet cells endocytose IgA originally secreted by the B lymphocytes present in the underlying lamina propria and this provide a major source of protection against microbial organisms in the gut lumen.[3]

Goblet cells are interspersed among the columnar absorptive cells of the intestinal epithelium. They increase in number toward the distal region of the small intestine.[4]

The epithelium of the small intestine is endodermal in origin. These endodermal cells differentiate into various types of secretory and absorptive cells. Remaining layers are derived from the splanchnic mesoderm. [5]

The endodermal epithelium of the gut proliferates at the $6^{\text {th }}$ week and completely occludes the gut lumen.[6] Over the next two weeks, vacuoles develop in this tissue and coalesce until the gut tube is fully recanalised. Finally, in the $9^{\text {th }}$ week of development, the definitive mucosal epithelium differentiates from the endodermal lining of the new gut lumen.

Villi appear in the duodenum and proximal jejunum by 7 weeks. The development of villi reaches the distal jejunum by 9 weeks and the distal ileum by 11 weeks. Primitive crypts appear between 10 and 12 weeks. Epithelial cells differentiate and form Enterocytes at about 9 weeks. Goblet cells are present in small numbers by 8 weeks. Enteroendocrine cells appear between 9 and 11 weeks and Paneth cells differentiate at the base of the crypts at about 11 and 12 weeks.[7]

The main objective of this study was to find out the exact time of appearance of goblet cells in the human small intestine and to follow the gradual development of the cells 
towards histological maturity. Various studies are available on different aspects of goblet cells in the adult human small intestine. However, only few researchers have reported on the time of appearance of goblet cells in the foetus.

\section{MATERIALS AND METHODS}

The present study was carried out in the Department of Anatomy, Regional Institute of Medical Sciences, Imphal. It was a one-time cross-sectional study conducted on aborted foetuses ranging in age from 9 weeks to 24 weeks of gestational age.

With due permission from the Ethical Society and proper consent of the concerned individuals 50 human foetuses, 26 males and 24 females, representing different gestational ages ranging from 9 weeks to 24 weeks were collected from the Department of Obstetrics and Gynaecology including PPP centre, RIMS, Imphal. The foetuses were mostly still-borns and a few were the products of induced abortions (under the provisions of the MTP Act of India, 1971).

Age of the foetuses was calculated from obstetrical history and by measuring the crown-rump length (CRL) based on KL Moore's Textbook of "The Developing Human, Clinically Oriented Embryology."

\begin{tabular}{|c|c|c|}
\hline Sl. No. & Gestational Age (Weeks) & CRL (mm) \\
\hline 1 & 9 & 50 \\
\hline 2 & 10 & 61 \\
\hline 3 & 12 & 87 \\
\hline 4 & 14 & 120 \\
\hline 5 & 16 & 140 \\
\hline 6 & 18 & 160 \\
\hline 7 & 20 & 190 \\
\hline 8 & 24 & 230 \\
\hline
\end{tabular}

\section{Procedure of Tissue Preparation}

Foetuses Collected were Dissected in the following Manner

Subcostal incisions were given on either side to open up the anterior abdominal wall. The incisions were extended downward and medially to meet each other at the pubic symphysis. After removing the anterior abdominal wall, the small intestine was identified and gently taken out. The upper end was detached at the pyloric end of the stomach and the lower end was cut at the ileocaecal junction.

Short segments of the small intestines were cut, and mesentery gently removed. The tissues were then subjected to tissue processing. Primary fixation was done in $10 \%$ Formalin for a period of 7 - 10 days followed by secondary fixation in Neutral Buffered Formalin. After satisfactory fixation, the tissues were trimmed and washed in $50 \%$ Alcohol. This was followed by the normal procedure of Dehydration, Clearing, Paraffin embedding, Paraffin block making, Sectioning, Mounting, Rehydration and Staining.

The Rotary Microtome was used for making serial sections of the specimen. Haematoxylin and Eosin stain was used for the histological study.

The stained slides were examined under the Light Microscope and those slides showing specific findings were photographed and stored for record and presentation. The histological findings were then compiled, and the results compared with the findings of previous researchers.

\section{RESULTS}

At 9 weeks, plenty of villi were seen projecting into the lumen of the small intestine. The epithelium covering the villi and the intervillous spaces was pseudostratified columnar in type (Fig. 1). Specimens from two foetuses at 9 weeks showed few goblet cells. No goblet cells were found in three specimens at 9 weeks (Fig. 2). At 10 weeks the epithelium became simple columnar with an increasing number of Goblet cells. However, a few specimens did not show any goblet cells.

At 12 weeks, all the specimens examined showed the presence of goblet cells (Fig. 3). Goblet cells were seen as large cells with an upper expanded part and a narrower base.

At 14 weeks, villi were better developed, and intestinal glands were seen in abundance. The epithelium was simple columnar in type. At this stage, plenty of goblet cells were observed on the villi and also in the upper part of the intestinal glands.

At 16 - 18 weeks, there was an increase in the number of villi and intestinal glands. The epithelium covering the villi and intestinal glands was simple columnar with numerous goblet cells (Fig. 4). Other epithelial cells such as enteroendocrine cells and Paneth cells were also observed. A lot of lymphocytes were seen infiltrating the mucosa at 20 weeks.

At 24 weeks, all the epithelial cells of the small intestines were observed clearly. Goblet cells were seen in plenty (Fig. 5).

\begin{tabular}{|c|c|c|c|c|}
\hline & $\begin{array}{c}\text { Age of Foetus } \\
\text { in Weeks }\end{array}$ & $\begin{array}{c}\text { No. of } \\
\text { Foetus }\end{array}$ & $\begin{array}{c}\text { No. of Foetus } \\
\text { with Goblet } \\
\text { Cells }\end{array}$ & $\begin{array}{c}\text { Percentage of } \\
\text { Foetus showing } \\
\text { Goblet Cells }\end{array}$ \\
\hline 1 & 9 weeks & 5 & 2 & $40 \%$ \\
\hline 2 & 10 weeks & 9 & 6 & $66.6 \%$ \\
\hline 3 & 12 weeks & 12 & 12 & $100 \%$ \\
\hline 4 & $14-18$ weeks & 13 & 13 & $100 \%$ \\
\hline 5 & $20-24$ weeks & 11 & 11 & $100 \%$ \\
\hline \multicolumn{5}{|c|}{ Statistical Analysis of Results } \\
\hline \multicolumn{5}{|c|}{} \\
\hline
\end{tabular}

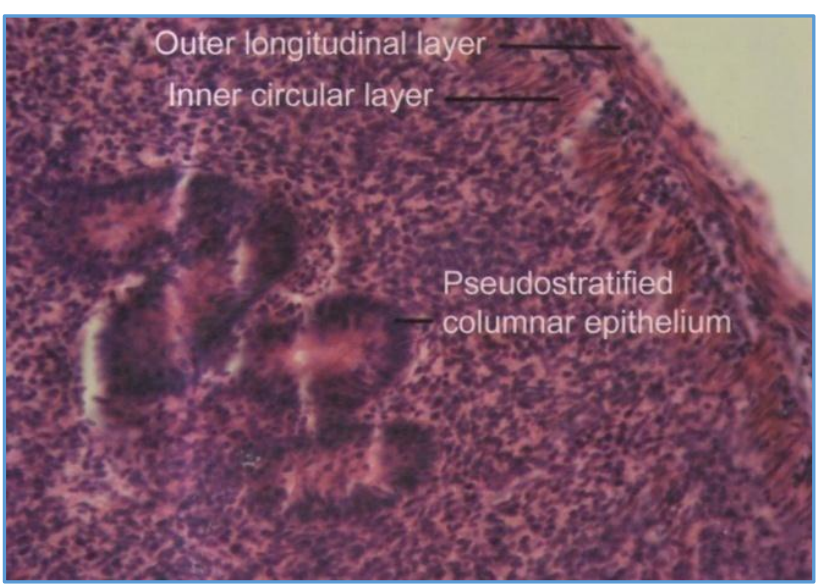

Figure 1. Longitudinal Section of Small Intestine at 9 Weeks (H and E Stain) 


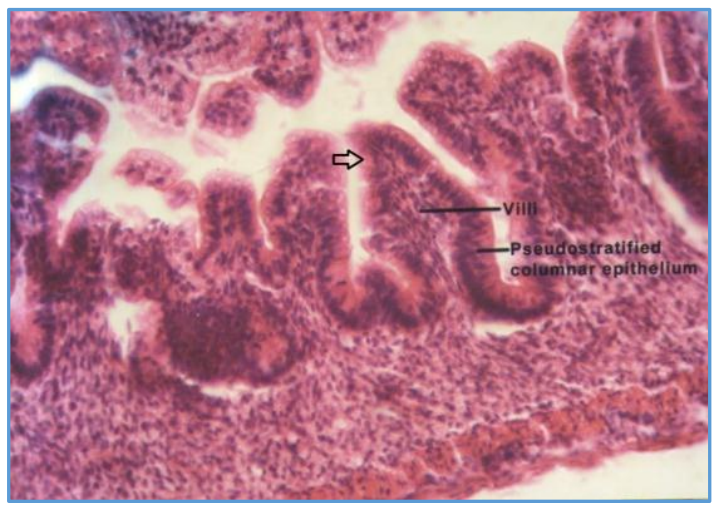

Figure 2. Small Intestine at 9 Weeks showing Few Goblet Cells indicated by Arrow (H and E Stain)

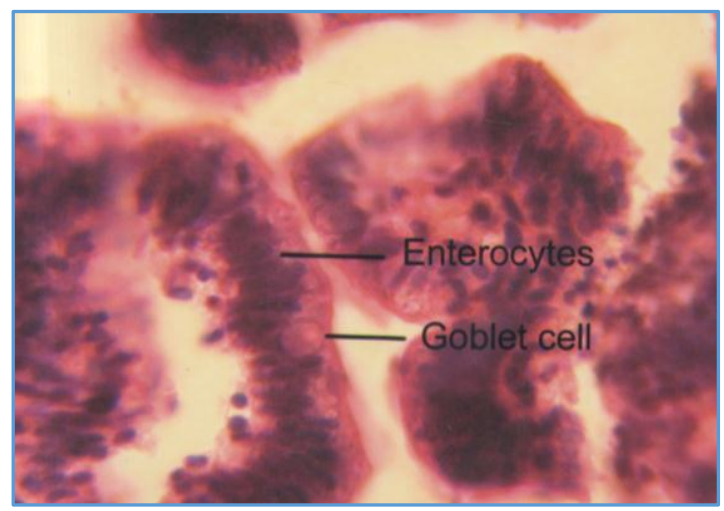

Figure 3. Transverse Section of Small Intestine at 12 Weeks (H and E Stain)

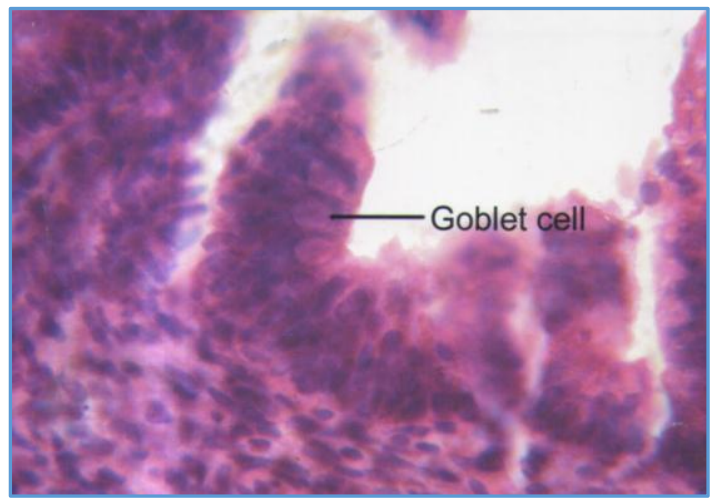

Figure 4. Cross-Section of Small Intestine at 16 Weeks (H and E Stain)

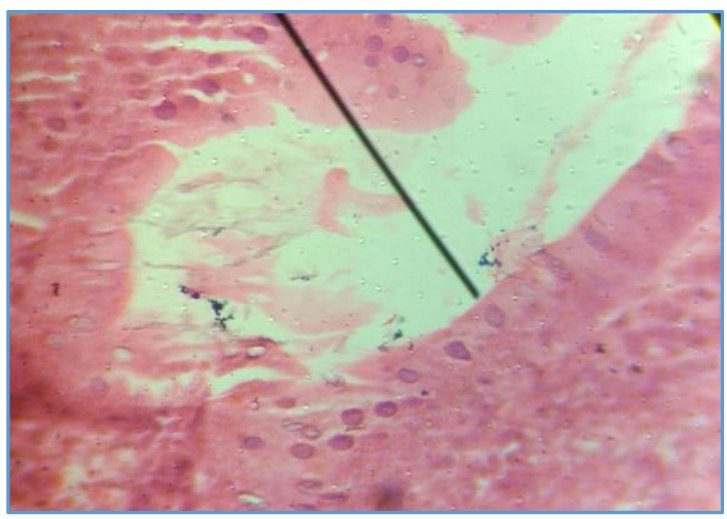

Figure 5. Cross-Section of Small Intestine at 24 Weeks showing Goblet Cells (H and E Stain)

\section{DISCUSSION}

The intestine plays an important role in the digestion and absorption of ingested food and the elimination of undigested food, microbes and microbial products. The functional integrity of the intestinal mucosal epithelial cells depends on the coordinated regulation of the mucus layer, the intercellular tight junction, epithelial cells and host innate and adaptive immune response.[8,9] The mucus layer overlying the epithelium secreted by the goblet cells promotes the elimination of gut contents and provides the first line of defense against physical and chemical injury caused by ingested food, microbes and the microbial products. The microbes and microbial products are recognised by the sensor system of the intestinal epithelial cells and the immune cells, activating the host innate defense system. Balanced and dynamic interactions among mucus layers, intestinal epithelial cells, microbiota and host immune defense are essential for the maintenance of the intestinal mucosal homeostasis. The disruption in the intestinal homeostasis results in the defective mucus barrier with increased permeability that results in inflammation and injury of the intestinal mucosal cells.[10]

The intestinal mucosal epithelium consists of four main cell types- absorptive enterocytes, goblet cells, Paneth cells and enteroendocrine cells- which undergo continuous cycles of renewal. The small intestinal epithelium is divided into two distinct compartments. The lower crypt compartment consists of pluripotent stem cells residing at the bottom of the crypt, recently identified by the stem cell marker Lgr5 and proliferating transit amplifying cells that differentiate into mature cell lineages (Absorptive, goblet and enteroendocrine cells) during migration toward the villus compartment. Paneth cells settle and undergo differentiation at the crypt bottoms.[11] Goblet cells appear early in development (In the human foetal small intestine, at 9 - 10 weeks' gestation) and relatively undifferentiated oligomucous and mature goblet cells are present in both the stratified and simple columnar epithelium; however, once the villi have formed, most goblet cells are indistinguishable from those found in the adult intestine. The goblet cell morphology is shaped by the distended theca containing the mucin granules located below the apical membrane. The proportion of goblet cells among epithelial cell types increases caudally from duodenum $(4 \%)$ to distal colon (16\%), similar to the increasing number of microbial organisms present in the proximal intestine to colon. ${ }^{[12]}$ There are fewer and smaller goblet cells in the intestine of the germ-free mice compared to those of conventionally raised mice indicating the microbial modulation of goblet cells.[13]

In most intestinal infections, induction of goblet cells and mucin synthesis and secretion occur frequently during acute phase. However, chronic infection results in the depletion of goblet cells and quantitative and qualitative alteration in mucus layers due to both altered synthesis and secretion of mucins and to microbial glycosidases and proteases.[8,9] Goblet cells are reduced in number and size in ulcerative colitis. Recent studies in mouse models of colitis highlight the importance of the role of mucin in maintaining the integrity of protective mucus barriers whose breakdown can result in colitis. Muc2-deficient mice with no morphologically identifiable goblet cells and absent Muc2 expression. 
(TFF3 and RELM $\beta$ were expressed) in the intestine recently were reported to have markedly deficient mucus layers with increased permeability and enhanced bacterial adhesion to the mucosal cell surfaces. These mice developed spontaneous colitis and were susceptible to DSS-induced colitis.[14,15]

The intestinal surface epithelium including goblet cells is continuously renewed from the stem cells at the crypt base with normal cell turnover between 3 and 7 days.[16] The stem cells give rise to all epithelial cells including the enterocytes, goblet cells, Paneth cells, enteroendocrine cells and Tuft cells. The enterocyte lineage is the primary cell lineage and its differentiation pathway is controlled by Notch signaling. When Notch signaling is blocked by $\gamma$ secretase inhibition, the Notch cytoplasmic component no longer enters the nucleus inhibiting transcriptional signaling and shifting differentiation into the secretory pathway.[17] Without further changes in signaling, goblet cells are the default result of this shift. Furthermore, the transcription factor SPDEF (SAM pointed domain ETS factor) is important for full maturation into goblet cells.[18]

Although, there is still limited knowledge of the cell biology of the goblet cells, it has become obvious that there are several types that function in different ways. In the small intestine, the goblet cell adjacent enterocytes supply the required bicarbonate for proper mucin unfolding. This is not the case in the large intestine where the goblet cell may supply bicarbonate via its own bestrophin-2 bicarbonate transporter.[19] Other examples are the intercrypt colonic surface goblet cells that continuously secrete mucus and by this build the inner mucus layer contrasts with the goblet cells in the upper part of the colonic crypts that can secrete by rapid compound exocytosis.[20,21] In order to understand goblet cell secretion and function, we first need to realise that these cells are more diverse and capable than has been previously anticipated.

Although, production and secretion of mucus are the main functions of the intestinal goblet cells, recent studies have shown that the small intestinal population is also able to acquire luminal antigens and present these to CD103+dendritic cells in the lamina propria.[22,23] Spontaneous antigen uptake was observed in the small intestine of conventionally raised mice, but not in the colon. However, in mice raised under germ-free conditions and in conventionally raised mice following oral treatment with antibiotics, spontaneous antigen uptake was also observed in the colon, suggesting that the uptake process is inhibited by the colonic microbiota.[22,24] Similar to regulation of mucus secretion, antigen uptake by the small intestinal goblet cells is augmented by cholinergic agonists and both baseline and agonist-induced antigen uptake is mediated via muscarinic receptor 4 . The ability of the intestinal goblet cells to acquire luminal antigens correlates with the expression of the $m 4$ receptor, i.e. higher expression in the small intestine compared with the colon and increased expression following antibiotics treatment. [24] The observed differences in carbachol-induced antigen uptake in the small and large intestine correlate with the observed differences in the sensitivity to carbachol-induced mucus secretion, suggesting that the two processes are regulated by similar mechanisms.

\section{CONCLUSION}

Goblet cells started appearing before 9 weeks of development in some foetuses. By 12 weeks of gestational age, goblet cells were present in the small intestine of all the foetal specimens studied.

\section{REFERENCES}

[1] Lipkin M, Sherlock P, Bell B. Cell proliferation kinetics in the gastrointestinal tract of man, cell renewal stomach, ileum, colon and rectum. Gastroenterology 1963;45:721-9.

[2] MacDonald WC, Trier JS, Everett NB. Cell proliferation and migration in the stomach, duodenum and rectum of man, radioautographic studies. Gastroenterology 1964;46:405-17.

[3] Wigley C. Microstructure of the small intestine. Gray's anatomy. 39th edn. Standring S, Ellis H, Healy JC, et al. London, Churchill Livingstone, 2005:1157-69.

[4] Eroschenko VP. diFiore's atlas of histology with functional correlations. $11^{\text {th }}$ edn. Lippincott Williams and Wilkins, 2005:341-2.

[5] Hamilton WJ, Mossman HW. Midgut and hindgut, Hamilton. $4^{\text {th }}$ edn. Boyd and Mossman's human embryology. London, The Macmillan Press Ltd., 1976:351-63.

[6] Larsen WJ. Development of the gastrointestinal tract. Human embryology. $2^{\text {nd }}$ edn. New York, Churchill Livingstone, 1997:245-8.

[7] Collins P. Development of midgut. 39th edn. Gray's anatomy. Standring S, Ellis H, Healy JC, et al. London, Churchill Livingstone, 2005:1256-9.

[8] Lievin-Le Moal V, Servin AL. The front line of enteric host defense against unwelcome intrusion of harmful microorganisms: mucins, antimicrobial peptides, and microbiota. Clin Microbiol Rev 2006;19(2):315-37.

[9] Dharmani P, Srivastava V, Kissoon-Singh V, et al. Role of intestinal mucins in innate host defense mechanisms against pathogens. J Innate Immun 2009;1(2):123-35.

[10] McGuckin MA, Eri R, Simms LA, et al. Intestinal barrier dysfunction in inflammatory bowel diseases. Inflamm Bowel Dis 2009;15(1):100-13.

[11] van der Flier LG, Clevers H. Stem cells, self-renewal, and differentiation in the intestinal epithelium. Annu Rev Physiol 2009;71:241-60.

[12] Karam SM. Lineage commitment and maturation of epithelial cells in the gut. Front Biosci 1999;4:D28698.

[13] Deplancke B, Gaskins HR. Microbial modulation of innate defense: goblet cells and the intestinal mucus layer. Am J Clin Nutr 2001;73(6):1131S-41S.

[14] Johansson ME, Phillipson M, Petersson J, et al. The inner of the two Muc2 mucin-dependent mucus layers in colon is devoid of bacteria. Proc Natl Acad Sci U S A 2008;105(39):15064-9.

[15] Van der Sluis M, De Koning BA, De Bruijn AC, et al. Muc2-deficient mice spontaneously develop colitis, indicating that MUC2 is critical for colonic protection. Gastroenterology 2006;131(1):117-29. 
[16] Barker N. Adult intestinal stem cells: critical drivers of epithelial homeostasis and regeneration. Nat Rev Mol Cell Biol 2014;15(1):19-33.

[17] Clevers H. The intestinal crypt, a prototype stem cell compartment. Cell 2013;154(2):274-84.

[18] Gregorieff A, Stange DE, Kujala P, et al. The etsdomain transcription factor Spdef promotes maturation of goblet and paneth cells in the intestinal epithelium. Gastroenterology 2009;137(4):1333-45.

[19] Yu K, Lujan R, Marmorstein A, et al. Bestrophin-2 mediates bicarbonate transport by goblet cells in mouse colon. J Clin Invest 2010;120(5):1722-35.

[20] Johansson ME. Fast renewal of the distal colonic mucus layers by the surface goblet cells as measured by in vivo labeling of mucin glycoproteins. PLoS One 2012;7(7):e41009.
[21] Specian RD, Neutra MR. Regulation of intestinal goblet cell secretion. I. Role of parasympathetic stimulation. Am J Physiol 1982;242(4):G370-9.

[22] McDole JR, Wheeler LW, McDonald KG, et al. Goblet cells deliver luminal antigen to $\mathrm{CD} 103+$ dendritic cells in the small intestine. Nature 2012;483:345-9.

[23] Howe SE, Lickteig DJ, Plunkett KN, et al. The uptake of soluble and particulate antigens by epithelial cells in the mouse small intestine. PLoS One 2014;9:e86656.

[24] Knoop KA, Mcdonald KG, McCrate S, et al. Microbial sensing by goblet cells control immune surveillance of luminal antigens in the colon. Mucosal Immunol 2015;8(1):198-210. 